\title{
PENGARUH PEMBELAJARAN KASTI KONVENSIONAL DAN MODIFIKASI TERHADAP KEMAMPUAN GERAK DASAR SISWA KELAS RENDAH
}

\author{
Muh. Ade Jaenudin \\ Email.muhamadadejaenudin@gmail.com
}

\begin{abstract}
ABSTRAK
Tujuan penelitian ini untuk menguji dan membandingkan pengaruh pembelajaran modifikasi permainan tradisional kasti dengan permbelajaran konvensional permainan kasti terhadap gerak dasar. Penelitian dilakukan dengan True-eksperiman randomized pre test post test control group desaign. Partisipan terdiri atas 50 siswa sekolah dasar kelas rendah yang terbagi atas kelompok pembelajaran modifikasi permainan tradisional kasti dan kelompok pembelajaran konvensional permainan kasti. Treatmen dilakukan selama 16 kali pertemuan. Gerak dasar dilakukan dengan melakukan pengetesan terhadap kemampuan lempar targer, lempar tangkap, memukul bola dan tes lari 50m. Data dianalisis dengan menggunakan uji-T. Hasil analisis menunjukkan bahwa pembelajaran modifikasi permainan tradisional kasti berpengaruh signifikan terhadap kemampilan gerak dasar. Berdasarkan hasil rerata dapat disimpulkan bahwa pembelajaran kasti dengan modifikasi mencapai hasil yang lebih baik jika dibandingkan dengan pembelajaran dengan cara konvensional.
\end{abstract}

Kata Kunci: Modifikasi Permainan, Gerak dasar, kasti 


\section{Jurnal Ilmu Keolahragaan Volume II Nomor 2 Oktober 2019 \\ Muh. Ade Jaenudin \\ Tersedia di: http://jurnal.untan.ac.id/index.php/jilo}

\section{PENDAHULUAN}

Rhoden (2006) menunjukkan bahwa pendidikan jasmani berpengaruh pada peningkatan kecerdasan emosional pelajar, menurut McNamee (2005) hal nilai dalam pendidikan jasmani mencakup nilai sosialisasi dan akulturasi. Sementara itu, Medcalf, Marshall, dan Menurut Wuest \& Buschner (2003), nilai yang dapat diajarkan dalam pendidikan jasmani mencakup nilai kerjasama, disiplin diri, permainan yang adil (fair-play), pengendalian emosional, kerja kelompok, kepercayaan diri, dan keyakinan diri. Beberapa pendapat tersebut menunjukkan bahwa nilai yang dapat ditransfer melalui pendidikan jasmani sangat kompleks mulai dari kecerdasan emosional, kerjasama, disiplin, percaya diri, keyakinan diri, pengendalian emosi yang dapat diterapkan dalam kehidupan masyarakat dalam proses akulturasi sebagai transfer nilai dalam permainan atau olahraga dalam masyarakat. Nilainilai dapat dicapai dengan melalui proses penyelenggaraan pendidikan jasmani yang bermakna (Russel, 2004)

Permasalahan berikutnya adalah bagaimana upaya untuk meningkatkan kemampuan gerak dasar siswa untuk menggunakan cara-cara kreatif agar keikutsertaan anak dalam aktivitas jasmani meningkat. Peneliti telah melakukan studi pendahuluan berkaitan dengan kemampuan gerak dasar dan memukul bola di kelas bawah. Hasil penelitian menunjukkan bahwa kemampuan siswa memukul, dan menangkap bola kasti kelas atas yang sukses hanya $60 \%$, sedangkan siswa pada siswa kelas rendah hanya $30 \%$. Berdasarkan hasil tersebut dapat dipahami bahwa kenyatataannya siswa dalam penguasaan gerak dasar masih rendah pada siswa baik kelas atas maupun kelas bawah. Sehingga kemampuan motorik dasar merupakan hal yang perlu mendapat perhatian.

\begin{abstract}
Modifikasi permainan kasti berpotensi untuk memupuk berbagai gerak dasar, maka perlu adanya pengembangan modifikasi permainan untuk meningkatkan gerak dasar. Mengapa dimodifikasi, karena terdapat permasalahan yang muncul dalam permainan kasti adalah luas lapangan, bola yang keras, jarak antar base yang panjang, jumlah pemain yang terlalu banyak yang menyebabkan kesempatan untuk berlari, memukul dan lempar tangkap sedikit. Bola disajikan dengan dilemparkan (under) merupakan kesulitan sendiri bagi anak ketika koordinasi mata tangan dan keterampilan open skill masih kurang. Kondisi-kondisi tersebut menyebabkan proses pendidikan jasmani menjadi rendah yang mengakibatkan rendahnya kualitas gerak baik itu pada ranah psikomotor.
\end{abstract}

METODE

\begin{tabular}{rrrr}
\multicolumn{2}{c}{ Penelitian ini merupakan } \\
penelitian eksperimen
\end{tabular} mengunakan sampel siswa kelas rendah sekolah dasar (kelas 1-3 siswa SDN Karyajaya Kecamatan Bojongpicung). Jumlah sampel adalah 50 Siswa yang tebagi atas dua kelompok. Desain penelitian mengunakan The Randomized Pretest-Posttest Control Group design dalam Fraenkel (2011, hlm. 272). Durasi waktu pembelajaran 70 menit per kali pertemuan selama 16 kali. Instrument penelitian terbagi atas dua (2) macam tes dan pengukuran, pertama tes kemampuan gerak dasar yang terdiri dari tes kecakapan (melempar, menjaga, memukul, dan lari).

\section{HASIL PENELITIAN}

Penelitian ini menggali informasi dan membuktikan secara ilmiah pengaruh permainan bola kasti konvensional yang belum dimodifikasi terhadap gerak dasar. Gerak dasar dalam penelitian ini adalah kemampuan lempar tangkap, melempar target, memukul bola dan lari $50 \mathrm{M}$. Treatment yang dilakukan dalam penelitian ini adalah pembelajaran permainan dengan modifikasi dan 
permainan konvensional dalam olahraga permainan tradisional bola kasti. Dipilihnya permainan bola kasti ada beberapa alasan diantaranya: permainan ini masuk dalam kurikulum secara nasional, permainan ini mudah untuk dilaksanakan dan banyak siswa yang dapat berpartisipasi, alasan berikutnya merangsang siswa untuk melatihkan gerak dasar seperti lari dan lempar tangkap.

Kedua variabel tersebut berdasarkan hasil tes dan pengukuran dan pengamatan kemudian dicari Skor $\mathrm{T}$ untuk dilakukan analisis lebih lanjut. Setelah t skor diperoleh kemudian dilakukan analisis deskriptif pada Tabel 1.

Tabel 1 Diskriptif Hasil Penelitian Kelompok Konvensional dan Modifikasi

\begin{tabular}{|l|l|l|r|r|}
\hline \multicolumn{5}{|c|}{ Descriptive Statistics } \\
\hline \multirow{3}{*}{ Gerak_dasar } & kel_eksperimen & Mean & Std. Deviation & N \\
\cline { 2 - 5 } & konvensional pre test & 46.0925 & 4.21735 & 25 \\
\cline { 2 - 5 } & konvensional post test & 46.7757 & 3.87635 & 25 \\
\cline { 2 - 5 } & modifikasi pre test & 46.1122 & 4.03040 & 25 \\
\cline { 2 - 5 } & modifikasi posf test & 50.0000 & 4.78421 & 25 \\
\cline { 2 - 5 } & Total & 47.2451 & 4.48028 & 100 \\
\hline
\end{tabular}

Berdasarkan data di atas dapat dijelaskan bahwa nilai rerata kelompok konvensional pre tes dan post tes secara berurutan 46.0925 dan 46.7757 untuk nilai keterampilan gerak dasar. Sedangkan untuk kelompok modifikasi pre test dan post test 46.1122 dan 50.0000 untuk nilai keterampilan gerak dasar. Nilai rerata gerak dasar semua kelompok eksperimen dilihat dari rerata sama yaitu 50 .

Berdasarkan perhitungan data hasil penelitian hipotesis dalam penelitian ini kemudian akan dijawab. Hipotesis pertama dan kedua adalah: "Terdapat pengaruh yang signifikan pembelajaran modifikasi permainan tradisional kasti dan pembelajaran konvensional kasti terhadap gerak dasar"

Tabel 2.Analisis UJI T

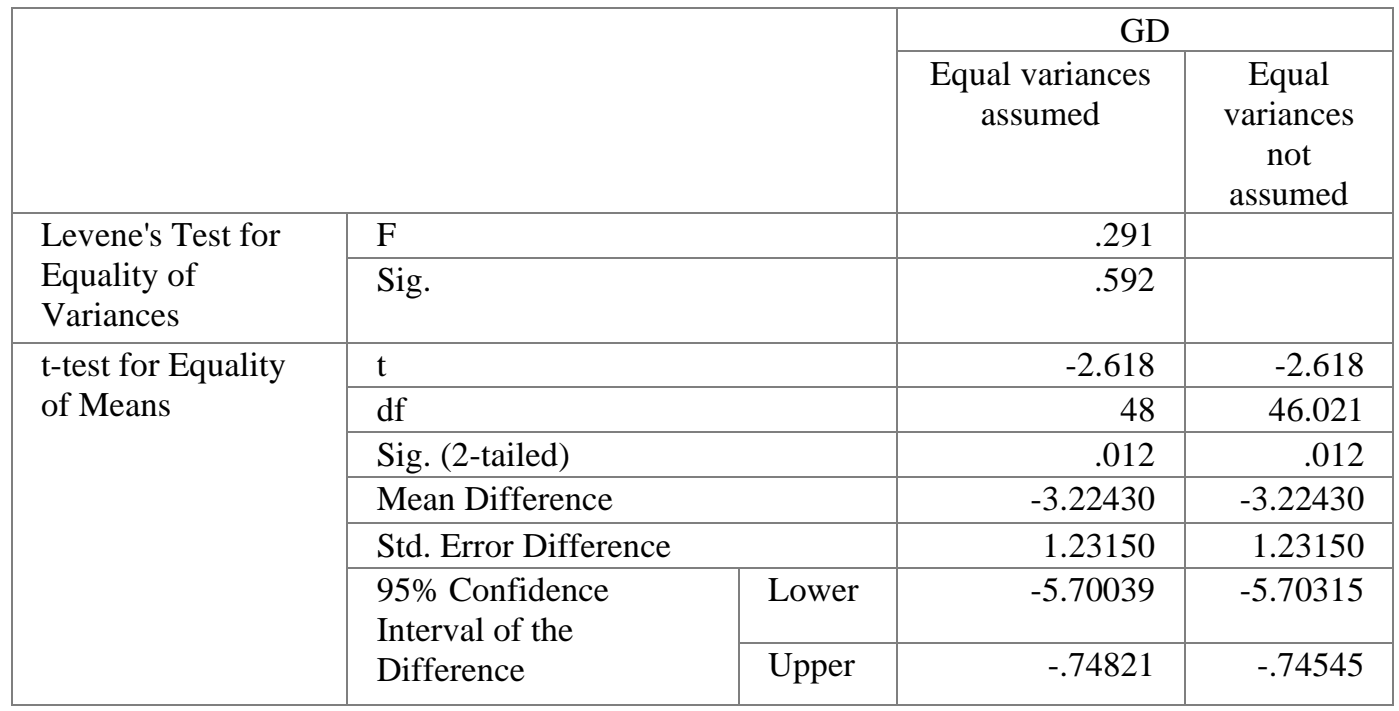




\section{Jurnal Ilmu Keolahragaan Volume II Nomor 2 Oktober 2019 \\ Muh. Ade Jaenudin \\ Tersedia di: http://jurnal.untan.ac.id/index.php/jilo}

Tabel 2 terhadap dua kelompok eksperimen pre test post test ternyata Hipotesis dapat dilihat dari angka signifikasi semua uji menunjukkan 0.012 , hal ini dapat diartikan bahwa terdapat perbedaan hasil antara hasil pre test post test dari masing masing kelompok eksperimen. Dilihat dari hasil ini dan dilihat pada perbedaan mean dapat disimpulkan secara meyakinkan bahwa dengan menggunakan modifikasi memberikan dampak yang lebih baik.

\section{PEMBAHASAN}

Bahwa hasil penelitian
menunjukkan pembelajaran modifikasi hasilnya lebih baik. Hal ini ditunjukkan dengan hasil sig. hitung adalah .012. hasil ini memberikan bukti bahwa dengan modifikasi ada hal baru dan lebih menarik. Hal baru dimaksudkan adalah. Bahwa dengan penambahan base memberikan kesempatan kepada siswa untuk merasakan sukses yang lebih dibandingkan hanya 3 base. Cara mematikan tidak dipukulkan tetapi di bakar ke tempat yang dituju memberikan efek psikologis yang lebih positif bila dibandingkan dengan bola dipukulkan ke badan. Khsus peserta putri akan sangat tidak senang dan sakit ketika bola yang diganti dengan bola lebih besar dan ringat. Serta tidak di pukulkan ke badan merupakan cara agar siswa tidak merasa takut, terutama siswa putri. Berikutnya hasil post test menunjukan bukti yang nyata. Bahwa terjadi kenaikan hasil posts test terhadap keterampilan gerak dasar.

Dalam eksperimen ini siswa belajar untuk bermain yang meliputi kegiatan, berpersepsi, memahami, pengambilan keputusan dan bergerak dalam kontek bermain kasti. Kasti dengan konvensional dan kasti dengan peraturan dan lapangan yang dimodifikasi. Upaya untuk bisa bermain dan bermain dengan senang muncul disana adalah kemampuan untuk memutuskan apa yang harus dilakukan.

Katian dengan pengambilan keputusan terkait dua penelitian yang dilakukan oleh Garbett, Tim J; Carius, Josh; Mulvey, Mike (Nov 2008), penelitian ini membutktikan bahwa kebugaran anak akan berkorelasi dengan kemampuan lamanya konsentrasi. McMorris, Terry; Graydon, Jan (Mar 1996) penelitian yang cukup lama ini menggambarkan bahwa dengan latihan maka kecepatan pengembilan keputusan akan meningkat.

Kasti merupakan permaianan yang selalu ada dalam kurikulum pendidikan jasmani. Kasti sebagai salah satu bahan atau subyek matter dalam kurikulum menjadi sebuah momok bagi siswa yang takut sakit terkena bola. Jika kasti ini tetap pada aturan dan segala perlengkapan yang lama maka, akan timbul persepsi negatit pada diri anak bahwa olahrag itu melelahkan dan menyakitkan. Hal ini akan berdampak pada keikutsertaan siswa terutama putra pada pelajaran pendidikan jasmani. Modifikasi yang dilaksanakan memberikan suasana dan kesenangan baru pada siswa. Ketika pembelajaran ditingkatkan kualitasnya dengan cara meningkatkan angka partisipasi siswa maka secara otomatis siswa akan sejahtera dalam mendapatkan pengalaman bergerak.

Adapun pembahasan hasil penelitian sebagai berikut:

Perbedaan Pengaruh Pembelajaran Modifikasi Permainan Tradisional Kasti Terhadap Gerak Dasar.

Benar terjadi ketika kasti dimodifikasi maka siswa akan mengalami kemudahan dalam bermain. Terlebih subyek penelitian dalam penelitian ini adalah siswa sekolah rendah. Sehingga siswa pada tahap ini masih belum memiliki keterampilan gerak yang sempurna. Ternyata dengan disederhanakan dan dipermudah hasil penelitian menyatakan memiliki pengaruh yang signigikan terhada gerak dasar. Faktor yang mempengaruhi modifikasi ini bisa diterima siswa kelas rendah karena jarak yang dekat, jangkauan lebih dekat, 


\section{Jurnal Ilmu Keolahragaan Volume II Nomor 2 Oktober 2019 \\ Muh. Ade Jaenudin \\ Tersedia di: http://jurnal.untan.ac.id/index.php/jilo}

lapangan yang lebih kecil, berbeda dengan lapangan permainan kasti yang sebenarnya.

Terdapat penelitian yang hampir sama dengan penelitian ini kaitan dengan pembahasan putra dan putri di bidang bola voley Miller, Margie Lynne (1997), meneliti dengan membandingkan tiga kelompok eksperimen, kelompok pertama denga menggunakan reguler biasa, kedua kelompok dengan bola volley kecil, ketiga dengan pelatih volley. Ketiga kelompok meningkat pada kemampuan servis dan pasing, dan kelompok yang paling baik adalah kelompok yang menggunakan pelatih. Yang terakhir kelompok putra hasilnya lebih baik dibandingkan kelompok putri. Bahwa siswa putri akan memiliki hasil yang lebih rendah dibandingkan putra. Salah satu alasan yang dapat diajukan adalah putri memiliki ketidaksenangan dengan gerak. Ketidak senangan dengan gerak diperoleh dari pengalaman. Demikian juga hasil penelitian yang dilakukanoleh Rudd, James R; Barnett, Lisa M; Butson, Michael L; Farrow, Damian; Berry, Jason; et al. (Oct 2015), Savage, Nancy Heather (2002). bahwa gerak dasar putra lebih baik dibandingkan dengan putri . Pahler, Thomas Robert, (1995) membandingkan keterampilan gerak dasar pada anak yang sekolah di tempat sekolah yang berbeda, home school, sekolah khusus dan sekolah umum negeri di Arizona. Hasil penelitian menunjukan (1) putra lebih baik dari pada putri (2) tidak ada perbedaan keterampilan motorik kasar pada putra diliha dari sekolahnya (3) putri yang home school keterampilan motorik kasar lebih rendah dibandingkan yang di sekolah umum. (4) dan lebih tinggi variasinya penguasaan keterampilan motorik siswa putri pada sekolah home schooling

Hasil penelitian gerak dasar dari modifikasi permainan tradisonal kasti dengan rerata 50.00. Berdasarkan ketentuan yang ditetapkan maka gerak dasar pada modifikasi permainan tradisonal kasti telah memenuhi ketentuan sehingga gerak dasar siswa kelas rendah meningkat. Faktor yang dapat mempengaruhi gerak dasar pada modifikasi permainan tradisional kasti bisa diberikan pada siswa kelas rendah sehingga hasilnya signifikan.

Hal berikutnya bahwa pengusaaan gerak dasar sangat dipengaruhi oleh lingkungan. Penelitian lain menunjukkan bahwa yang memiliki keterampilan motorik lebih baik juga memiliki persepsi diri yang lebih baik Graves, Delbert (2008). Orang tua memiliki peran yang penting dalam peningkatan kemampuan gerak dasar anak. Menyimpulkan bahwa keterlibatan orang tua memberikan hubungan yang erat tehadap aktivitas anak. Robert, Darren Luke. (1999). Kemampuan keterampilan run, hop, and one foot balance dan juga terjadi peningkatan yang signifikan terhadap for running, hopping, and one foot balancing, tetapi tidak terhadap kemampuan menendang perlu pembelajaran baik dalam forum resmi ataupun lingkungan bebas dalam kontek bermain yang aman.

Hasil penelitian ini memberikan gambaran bahwa bagaimanapun proses pembelajaran yang berkualitas akan memberikan pengaruh kepada siswa. Sehingga ketertinggalan keterampilan gerak harus diatasi dengan cepat. Kemampuan guru dalam menciptakan suasana belajar yang tepat akan memberikan dampak yang baik terhadap perkembangan gerak siswa, hal ini mengacu pada penelitian yang dilakukan oleh (Savage, Nancy Heather, (2002) di atas.

Pada kelas rendah berdasarkan penelitian yang dilakukan oleh Cook, Ryan (2012) tidak ada perbedaan kemampuan motorik pada gerak lokomotor. Hal ini dapat terjadi Karena pengaruh pembelajaran. Penelitian di atas semakin menguatkan bahwa pembelajaranyang dilakukan terhadap siswa akan memiki dampak. Bagaimana memahami gerak, mengidentifikasi kesalahan gerak, dan bagaimana membetulkan adalah proses 


\section{Jurnal Ilmu Keolahragaan Volume II Nomor 2 Oktober 2019 \\ Muh. Ade Jaenudin \\ Tersedia di: http://jurnal.untan.ac.id/index.php/jilo}

belajar untuk menjadi bisa. Kesadaran akan kebutuhan gerak secara individu akan terlaksana ketika siswa diberi kesempatan untuk mencoba dan melakukan gerak yang dimaksud dalam lingkungan yang mendukung. Modifikasi adalah cara yang ampuh untuk melaksanakan hal tersebut, dengan modifikasi maka anak akan lebih difasilitasi baik secara fisik ataupun psikologis. Ada bukti baha siswa yang memiliki keterampilan gerak yang lebih, maka akan lebih aktif dibandingkan dengan siswa yang kurang penguasaan dalam keterampilan gerak Williams, Harriet G; Pfeiffer, Karin A; O'neill, Jennifer R; Dowda, Marsha; Mciver, Kerry L; et al. (Jun 2008). Dilakukan pengetesan terhadap kemampuan six locomotor and six object control skills; scores were categorized as locomotor, object control.

Pembahasan ini memberikan gambaran bahwa penguasaan keterampilan gerak dasar yang dimanifestasikan dalam lokomotor, non lokomotor dan manipulative adalah keterampilan yang sangat penting. Penguasaan terhadap keterampilan ini akan membelaki siswa untuk hidup aktif, dan mendapat manfaat kesehatan dari hidup aktif tersebut. Hidup aktif baik dengan olahraga ataupun yang lain. Hidup aktif memberikan keuntungan secara jasmani (bugar) dan memilik hubungan yang baik dalam berinteraksi dalam aktivitas jasmani (sosial), sehingga secara keseluruhan akan terbangun jasaman dan rohani yang baik. Kebugaran fisik yang baik memiliki dampak yang baik terhadap lamanya siswa dapat berkonsentrasi dalam belajar.

Perbedaan pengaruh pembelajaran permainan konvensional kasti terhadap gerak dasar

Kemampuan gerak dasar merupakan modal dasar bagi siswa untuk mengikuti aktivitas jasmani. Baik permainan, seni, olahraga ataupun untuk transfer belajar keterampilan hidup yang lain. Ternyata dengan hasil penelitian menyatakan bahwa tidak ada perbedaan antara pretes dan posttest ketika menggunakan metode konvensional. Ada beberapa kemungkinan yang menyebabkan hal ini. Diantaranya siswa takut dengan bola yang keras, kedua lapangan terlalu luas sehingga ada keengganan untuk berlaji jauh, terlebih hanya ada 3 pancang yang saling berjauhan. Kenyataan di lapangan siswa banyak yang berhenti pada tiang pancang kedua dan enggan untuk kembali ke base awal. Dengan kondisi ini maka kesempatan siswa untuk lari antar pancang, dan kesempatan untuk melakukan lempar tangkap menjadi semakin rendah. Sehingga proses belajar berlari lempar tangkap akan semakin sedikit. Kaitan dengan hal ini dapat dijelaskan dalam sebuah penelitian bahwa semakibn tinggi intensitas permainan maka kemampuan untuk mengambil keputusan (gerak/keterampilan gerak) akan semakin tinggi Fontana, Fabio Eduardo (2007). Sementara dalam desain kasti konvensional siswa sudah mengalami keengganan untuk berlari, sehingga intensitas permainan menjadi menurun.

Selanjutnya Hepler, Teri J; Feltz, Deborah L (Mar 2012): Tujuan peneltian ini adalah untuk menghubungkan antara keyakinan diri terhadap kemampuan dan kecepatan melakukan pengambilan keputusan dalam permainan baseball. Berdasarkan penelitian yang dilakukan diperoleh hasil yang signifikan, terbukti bawa keyakinan diri secara konsisten mempengarui dalam kinerja dalam melaksanakan keputusan. Kaitannya dengan hal ini adalah bahwa dalam permainan dibutuhkan kemampuan untuk memutuskan apa yang harus dilakukan, kemana, dengan siapa dan dengan cara apa. Dalam kontek bermain siswa dipaksa untuk memutuskan sendiri dalam waktu yang sangat cepat ketika ingin mematikan lawan ataupun mendapat point. Bagi siswa pemula dalam bermain situasi ini 


\section{Jurnal Ilmu Keolahragaan Volume II Nomor 2 Oktober 2019 \\ Muh. Ade Jaenudin \\ Tersedia di: http://jurnal.untan.ac.id/index.php/jilo}

tidak mudah, berdasarkan hasil peneltian dalam penelitian ini diketahuui bhawa dengan menggunakan modifikasi hasilnya lebih baik. Hal ini dimungkinkan karena keterlibatan yang lebih besar disebabkan adanya jumlah tiang/base yang lebih banyak dan kesempatan untuk bergerak menjadi lebih banyak.

Kaitan dalam penelitian ini ketika siswa masih pada posisi kelas rendah, maka keterampilan pengembilan keputusan akan berlangsung ketika telah memiliki gerak dasar yang cukup. Menjadi bahan diskusi adalah bagaimaan keterampilan gerak dasar akan naik jika kesempatan untukmencoba berlari dan lempar tangkap dihalangi oleh jarah yang jauh karena panjang lapangan, hal ini juga diperlukan keyakinan diri yang menuntut kepercayaan diri untuk melaksanakan keputusan. Melihat apakah keputusan yang dilaksanakan itu sukses ataupun tidak?, itu merupakan proses belajar. Sehingga dengan seting pembelajaran bermain maka akan merangsang anak untuk dengan cepat merespon dan melaksanakan gerakan yang dianggap perlu berdasarkan pengalaman, pemahaman yang dimiliki oleh siswa.

Penelitian lain yang mendukung perihal pengambilan keputusan adalah yang dilakukan oleh Garbert.et.all (2008) bahwa dengan menggunakan video ternyata dapat dipergunakan untuk membantu atlet dalam belajar semakin mengefektifkan pengambilan keputusan. Berdasarakan hasil penelitian ini dapat dipahami bahwa untukmelaksanakan pengambilan keputusan tetap harus memiliki kemampuan gerak dasar yang baik. Hal yang tidak kealah penting adalah pengalaman yang menyenangkan selama bermain, kedua pengelaman mengalami sukses dalam permainan. Agar dapat sukses dalam permainan harus memiliki keterampilan gerak dasar yang baik.

\section{KESIMPULAN}

Permainan modifikasi kasti berpengaruh lebih baik terhadap keterampilan gerak dasar, dibandingkan dengan permainan bola kasti yang konvensional. Hasil penelitian ini memberikan informasi mengenai makna permainan bola kasti untuk melakukan intervensi terhadap kemampuan gerak dasar. Sehingga permainan kasti konvensional ataupun modifikasi dapat dipergunakan untuk mengajarkan keterampilan gerak dasar. Dengan melihat efektivitas berdasarkan uji statistic dan efisiensi ketersediaan lapangan bagi sekolah dasar maka permainan kasti modifikasi lebih dianjurnkan. Bahwa permainan kasti modifikasi dapat dipergunakan dan sudah dapat diberikan kepada siswa sekolah rendah, hal ini dapat dilihat dari keterlaksanaan, kepahaman siswa dalam bermain modifikasi kasti.

\section{DAFTAR PUSTAKA}

Cook, Ryan (2012) Fundamental Motor Development and Physical Activity Levels of Kindergarten Children in School District 61 Victoria, BC. University of Victoria (Canada), ProQuest Dissertations Publishing, 2012. MR94788. http://eresources.perpusnas.go.id:2057/d ocview/1441026012/abstract/C19 5E5AABC7E443FPQ/53?accoun tid $=25704$

Fontana, Eduardo Fabio. (2007) The Effects Of Exercise Intensity On Decision Making Performance Of Experienced And Inexperienced Soccer Players. University Of Pittsburgh. ProQuest Dissertations Publishing, 2007. 3270093.

Fraenkel (2011) How to Design And Evaluate Research In Education. San Francisco State University, Mc Graw-Hill.

Garbett, Tim J;Carius, Josh;Mulvey, Mike. (Nov 2008). does improved decision making ability reduce the 
physiological. Journal of Strength and Conditioning Research: 22, 6; ProQuest pg. 2027

Graves, Delbert. Stephen F. Austin (2008). The relationship between perceived physical competence and fundamental motor skill performance in young childrenState University, ProQuest Dissertations Publishing, 2008. 1485040. http://e-

resources.perpusnas.go.id:2057/d ocview/739669786/abstract/4746 D84845394028PQ/8?accountid= 25704.

Hepler, Teri J;Feltz, Deborah L. (2012) Path Analysis Examining SelfEfficacy and Decision-Making Performance on a Simulated Baseball Task. Research Quarterly for Exercise and Sport; Mar 2012; 83, 1; ProQuest pg. 55

McMorris, Terry;Graydon, Jan.(1996). The effect of exercise on the decision-making performance of experienced and inexperienced soccer. Research Quarterly for Exercise and Sport; Mar 1996; 67, 1; ProQuest pg. 109

Mcname (2005) The Nature And Values Of Physical Education. Physical Education: Essential Issues

Medcalf (2006) Exploring the relationship between physical education and enhancing behaviour in pupils with emotional behavioural difficulties. University of Worcester, School of Sport and Exercise Science

Miller, Margie Lynne. (1997). The effects of modified volleyballs on performance and skill technique of fifth graders. University of Kansas, ProQuest Dissertations Publishing, 1997. 9811367.
Pahler, Thomas Robert. (1995) A comparison of the fundamental motor skill abilities of Arizona children in alternative school settings. Northern Arizona University, ProQuest Dissertations Publishing, 1995. $9529988 . \quad$ http://eresources.perpusnas.go.id:2057/d ocview/304266754/abstract/40C D487BB961434FPQ/19?accounti $\mathrm{d}=25704$

Robert, Darren Luke. (1999) The effects of a preschool movement program on motor skill acquisition, movement concept formation, and movement practice behavior. West Virginia University, ProQuest Dissertations Publishing, 1999. 3002991. http://eresources.perpusnas.go.id: 2057/docview/304535161/abstra ct/40CD487BB961434FPQ/14?a c countid $=25704$

Rudd, James R; Barnett, Lisa M; Butson, Michael L; Farrow, Damian; Berry, Jason; et al. (2015). Fundamental Movement Skills Are More than Run, Throw and Catch: The Role of Stability Skills: e0140224. PLoS One 10.10 (Oct 2015). http://eresources.perpusnas.go.id:2057/d ocview/1722473982/fulltext/474 6D84845394028PQ/5?accountid $=25704$

Russell (2004) Hoop frequency as a predictor of performance for softball bats. USA:Kettering University.

Santoso (2015) Menguasai Statistika Multivariat. Jakarta, Elex Komputindo Kelompok Gramedia, IKAPI.

Savage, Nancy Heather (2002). The effect of an object control motor skill intervention on the motor 
Tersedia di: http://jurnal.untan.ac.id/index.php/jilo

development of preschool and kindergarten children who are attending an urban elementary school. The Ohio State University, ProQuest Dissertations Publishing, 2002. 3049108.

http://eresources.perpusnas.go.id: 2057/docview/305501791/abstra ct/C195E5AABC7E443FPQ/36? accountid=25704.
Williams, Harriet G; Pfeiffer, Karin A; O'neill, Jennifer R; Dowda, Marsha; Mciver, Kerry L; et al. (2008) Motor Skill Performance and Physical Activity in Preschool Children. Obesity 16.6 (Jun 2008): 1421-6. http://eresources.perpusnas.go.id: 2057/docview/1030421249/abstr act/40CD487BB961434FPQ/43? accountid $=25704$ 